\title{
Towards a Typology of Virtual Communities of Practice
}

\author{
Line Dubé, Anne Bourhis, and Réal Jacob \\ HEC Montréal, Montréal, Québec, Canada
}

\section{Line.Dube@hec.ca Anne.Bourhis@hec.ca Real.Jacob@hec.ca}

\begin{abstract}
The literature is packed with "one-size-fits-all" advice on how to develop intentionally formed virtual communities of practice (VCoPs). However, a closer look at the literature shows that VCoPs often have unique "personalities." Based on an extensive review of the literature and a study of $18 \mathrm{VCoPs}$, we built a typology containing 21 structuring characteristics. We then used this typology and three of the studied VCoPs to show how different their basic natures are. Researchers and practitioners alike must not only recognize the diversity of VCoPs, but also identify challenges, strategies and practices that are contingent upon their specific characteristics.
\end{abstract}

Keywords: Virtual community of practice, virtual collaboration, knowledge management, typology, community characteristics, knowledge network

\section{Introduction}

As shown by both professional studies (e.g., Santos, Doz, \& Williamson, 2004; Warda \& Zieminski, 2000) and academic research (e.g., Leonard-Barton, 1995; Thornhill, in press), the capacity to innovate is currently one of the most critical elements in sustaining competitiveness. Researchers working in the field of organizational learning and knowledge management have shown that the process of innovation is widely influenced by the capacity of an organization to share tacit knowledge (Kodama, 2005; Nonaka \& Takeuchi, 1995). Communities of practice (CoPs), which are groups "of people who share a concern, a set of problems, or a passion about a topic, and who deepen their knowledge and expertise in this area by interacting on an ongoing basis" (Wenger, McDermott, \& Snyder, 2002, p.4), are seen as an innovative way to manage knowledge and sustain innovation (Lesser \& Prusak, 1999; Swan, Scarbrough, \& Robertson, 2002). With origins that take us back to the corporations of craftsmen in classical Greece and the guilds of the Middle Ages, where practices were transmitted mainly verbally, CoPs are not a new phenomenon (Wenger et al., 2002; Wenger \& Snyder, 2000). Organizations nowadays show increased interest because of the possibility of taking this old concept into the third millennium.

Material published as part of this journal, either on-line or in print, is copyrighted by the Informing Science Institute. Permission to make digital or paper copy of part or all of these works for personal or classroom use is granted without fee provided that the copies are not made or distributed for profit or commercial advantage AND that copies 1) bear this notice in full and 2) give the full citation on the first page. It is permissible to abstract these works so long as credit is given. To copy in all other cases or to republish or to post on a server or to redistribute to lists requires specific permission and payment of a fee. Contact Publisher@InformingScience.org to request redistribution permission.
Within global organizations and emerging forms of organizations, interacting face-to-face on a regular basis is costly and time-consuming. Since information and communication technologies (ICT) can transcend space and time, organizations are increasingly interested in exploiting their capabilities to support CoPs. Virtual communities of practice (VCoPs), without excluding face-to-face meetings, rely primarily on ICT to con- 
nect their members. A VCoP may use a large array of traditional media (phone, teleconference, fax, etc.) and more or less sophisticated technological tools, such as e-mail, videoconference, newsgroup, on-line meeting space, common database, Website, intranet (see Barrett, Cappleman, Shoib, \& Walsham, 2004 and Wenger, 2001) to establish a common virtual collaborative space. VCoPs are widely used as a knowledge management tool in a number of multinational corporations where they are now the norm rather than the exception (Ardichvili, Page, \& Wenthling, 2003; Wenger et al., 2002).

While CoPs were previously conceptualized as a phenomenon emerging spontaneously in organizations, it is now believed that organizations play a critical role in nurturing these communities (Brown \& Duguid, 2001; McDermott, 2000b; Newell, Galliers, \& Huang, 2003; Schwen \& Hara, 2003; Swan et al., 2002; Thompson, 2005; Wenger \& Snyder, 2000). The literature, and more specifically the professional press, is packed with "one-size-fits-all" advice for organizations interested in forming, developing and sustaining CoPs and VCoPs. This literature tends to assume that all communities are similar, the concepts of $\mathrm{CoP}$ and VCoP being usually treated as onedimensional constructs. But in order to nurture them to their full potential, organizations must understand what they are (Wenger \& Snyder, 2000). A closer look at existing VCoPs clearly reveals that, while they may share some common features, their various structuring characteristics, such as enrollment and geographic dispersion, make them unique. Moreover, as shown by the configurational school in management (Miller \& Whitney, 1999), within a particular context, different structuring characteristics or configurations of characteristics may be more or less conducive to success. Therefore, despite the increasing number of organizations using VCoPs, little is known about how to accompany them on the road to success (Ardichvili et al., 2003).

In our view, a preliminary but necessary step is to investigate the multi-faceted nature of VCoPs. We believe a focus on VCoPs is all the more important as they differ from CoPs because of their technological component; CoPs' and VCoPs' members experience very different environments because of the media through which they primarily interact and therefore face dissimilar realities that are better studied separately. For instance, building mutual knowledge, trust among members, and the sense of belonging, which all increase the likelihood of comprehension, open exchange and sharing, may be more difficult through computer-mediated interactions (Cramton, 2001; De Sanctis, Fayard, Roach, \& Jiang, 2003; Hildreth, Kimble, \& Wright, 2000; Pan \& Leidner, 2003). While virtual communities may come in all shapes or sizes, in this paper, we focus on VCoPs where members are assembled around an organizational practice. This type of virtual community is different from what is usually referred to as an on-line or Internet community where people share and learn on a casual basis on any given field of interest (health, pastime, etc.). We also exclude from our field of study the on-line communities mainly used by organizations as marketing tools as part of an on-line support repertoire. Even if the overall objective of these communities may be similar, a VCoP created in an organization may be highly disruptive and stressful for the people involved. As an organizational innovation - and even more so if participation becomes mandatory - it may force people into unfamiliar roles and ways of communicating/sharing, and into developing skills to create social ties through technology. What's more, the overall purpose which usually represents an organizational priority is surrounded by an organizational culture and existing organizational practices, and is exposed to political issues. Anyone of the abovementioned factors will cause a VCoP to experience a different set of challenges than those met by the typical on-line community.

Thus, the main objectives of this paper are to build a typology that will include the key structuring characteristics required to differentiate among different VCoPs and to illustrate the usefulness of the resulting typology by an investigation of three virtual communities of practice. We believe this is the groundwork for a deeper understanding of this novel form of knowledge management. This typology should (1) allow an accumulation of knowledge on various types of VCoPs evolv- 
ing in an organizational context, (2) improve sense making of empirical findings by considering the intrinsic characteristics of the VCOPs under study and, (3) provide practitioners with a useful framework to effectively describe, understand and manage VCoPs.

\section{A Typology of Virtual Communities of Practice}

The literature generally tends to treat the phenomena of CoPs and VCoPs as one-dimensional constructs, with undistinguishing features and undifferentiated identities. Some rare papers have tried to investigate the unique features of CoPs. For example, CoPs have been distinguished based on their initial purpose (e.g., American Productivity \& Quality Center [APQC], 2001) or their stage of development (e.g., Gongla \& Rizzuto, 2001). Wenger et al. (2002, chapter 2), however, seem to be the first to acknowledge that CoPs can take several forms: they identified size, life span, geographic dispersion, boundary span, creation process, and degree of institutionalized formalism as important characteristics whose combinations produce different types of CoPs. While this initial list is a useful beginning, a quick look at the literature shows that (1) it is not exhaustive and does not allow a complete differentiation among CoPs, (2) this list was created to distinguish among CoPs and does not take into consideration the specific characteristics introduced by ICT into VCoPs, and (3) Wenger and his colleagues fall short of demonstrating empirically the importance of these characteristics to the CoPs' daily life.

We believe that a finer understanding of VCoPs rests on a detailed comprehension of what they are. While they all must correspond to the basic definition of a VCoP, therefore share some common characteristics, the CoPs and VCoPs presented in the literature and in our study have unique personalities. Their basic identity can be defined by a series of characteristics. The term "structuring characteristics" refers to the rather stable elements of a VCoP, i.e., the elements that could be used to describe a $\mathrm{VCoP}$ if one wanted to take its picture at a given point in time. These compare to the "rather stable" elements such as age, height, weight, and eye color, commonly used to describe a person. Most of these characteristics are the fruit of design decisions made at the launching of the $\mathrm{VCoP}$ and together define what the $\mathrm{VCoP}$ really is. While some will positively influence the VCoP's life, others will create challenges that will need to be acted upon. The identification of these structuring characteristics is therefore a necessary condition to the successful management of VCoPs. These structuring characteristics are distinct from management decisions and actions that are taken afterwards, once the $\mathrm{VCoP}$ has been created, to control and/or counteract the negative effects of some structuring characteristics. Only two structuring characteristics, age and level of maturity, will change without any intervention. As time goes by, the VCoP will naturally age; the passage of time, however, does not necessarily guarantee a higher level of maturity.

To build this typology, we adopted a two-step methodology. First, an extensive review of conceptual and empirical papers was performed to identify the structuring characteristics of CoPs and VCoPs that were described in the literature. In order to identify all the relevant literature, we first used the CEFRIO research center's knowledge management article database, which is updated on a monthly basis. In addition, we conducted a literature search using ABI/Inform and Emerald Fulltext Library databases and used as reference $13 \mathrm{Web}$ sites specifically dedicated to the topic of communities of practice. We focused on papers discussing CoPs or VCoPs built in organizations for information sharing/building purposes. We did not include papers on communities at large (society) or on-line marketing communities since their nature and objectives are very different from our object of interest. We also included in this search the main books on the topic and, since the literature on VCoPs is rather scarce, also browsed through some articles about virtual teams that could help us define the virtual distinctiveness of a VCoP. Overall, over 163 articles (including journals, conference proceedings, and book chapters), 10 books, and 9 research reports were used as the foundation for the development of this typology. 
Through a careful analysis of the content of each document, we then systematically extracted all the features of VCoPs that we considered "structuring characteristics," as defined earlier. Characteristics were retained if they: (1) were mentioned at least once in the literature, and (2) were "structuring" in essence, i.e., could be used to describe the VCoP's form. Extensive face-to-face discussion among the authors helped resolve any initial disagreements relative to the retained characteristics; at this stage, however, the decision was made to include more rather than less characteristics.

As a second step, data were collected from 18 VCoPs implemented in 14 different organizations. This study is part of a larger research project managed by the CEFRIO research center. This action research project aimed at better understanding new forms of collaboration using ICT, such as virtual communities of practice. Throughout the project, a thorough follow-up of all VCoPs' activities was performed and measures were taken at different points in time (mainly through interviews, questionnaires and focus groups). In addition, feedback was constantly offered to the VCoPs and their organizations by the research team. More details about the methodology used in the entire research project can be found in Dubé, Bourhis, \& Jacob (2004) and Dubé, Bourhis, \& Jacob (2005).

Mainly two data collection sources were used for the part of the study reported here. First, when an organization expressed an interest in taking part in the project, an initial document was created. This document recorded the basic information on the community to be formed, such as the general objectives, the names of the community sponsor, leader and participants, the technology that would be used, the challenges that were likely to be faced, etc. The writing of this document was the first step in a rigorous logging process. A member of the research team was responsible for filing a detailed history of all cases from the very beginning, which was the second source of data. This research assistant called the VCoP coaches on a regular basis to keep abreast of any new developments. The coaches were members of the research team in charge of the day-to-day interactions with a specific organization and VCoP's leader. These coaches also called the research assistant to report any new critical incidents. All this information was rigorously recorded.

By performing a content analysis of all qualitative data gathered, we were then able to classify the $18 \mathrm{VCoPs}$ using the list of characteristics extracted from the literature. We compared and contrasted the VCoPs from our data set to see how similar and different they were. Comparing the studied VCoPs with our initial list of structuring characteristics allowed us to (1) identify redundancies in our list (e.g., the stage of development was an equivalent of the level of maturity); (2) clarify characteristics that were too broad or unclear (e.g., we separated members' selection into two characteristics: members' selection process and membership stability); and (3) add one characteristic, namely ICT availability. All the discussions among researchers were held face-to-face. The decisions to include, delete or clarify a structuring characteristic were made with the clear intention of describing as accurately and as extensively as possible the phenomenon under study.

These steps allowed us to select the 21 most meaningful structuring characteristics and to classify them into four categories. Table 1 shows the resulting typology. The closer a VCoP is to the right-hand side of each continuum, the more complex the community is, and the more challenges it may face during its life. While many of these characteristics could be used to describe both CoPs and VCoPs, some are exclusive to the latter. Table 1 also shows the main authors who have discussed or hinted at each of the characteristics. A definition of each structuring characteristic and its possible impacts on the future of the community follows. 


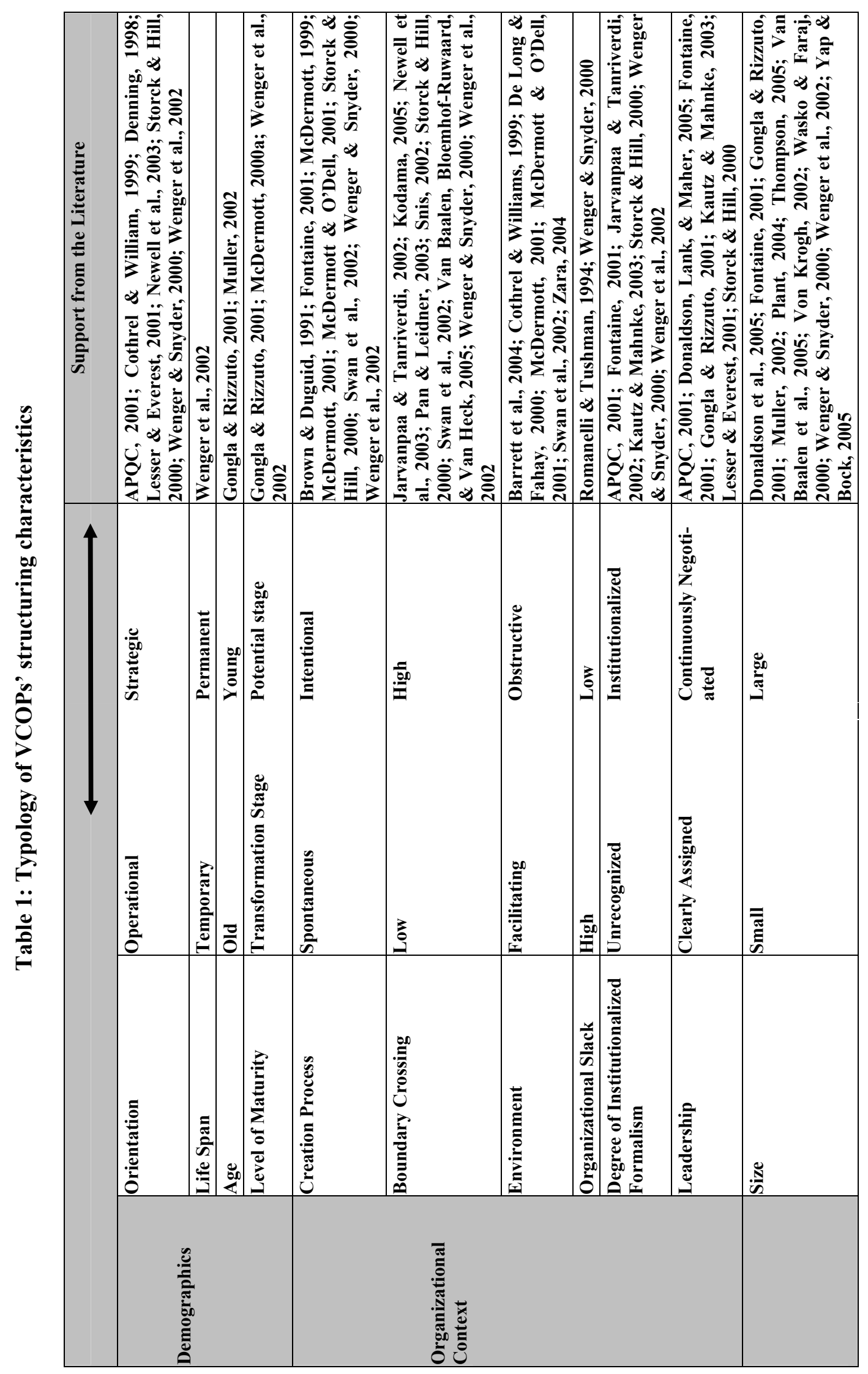




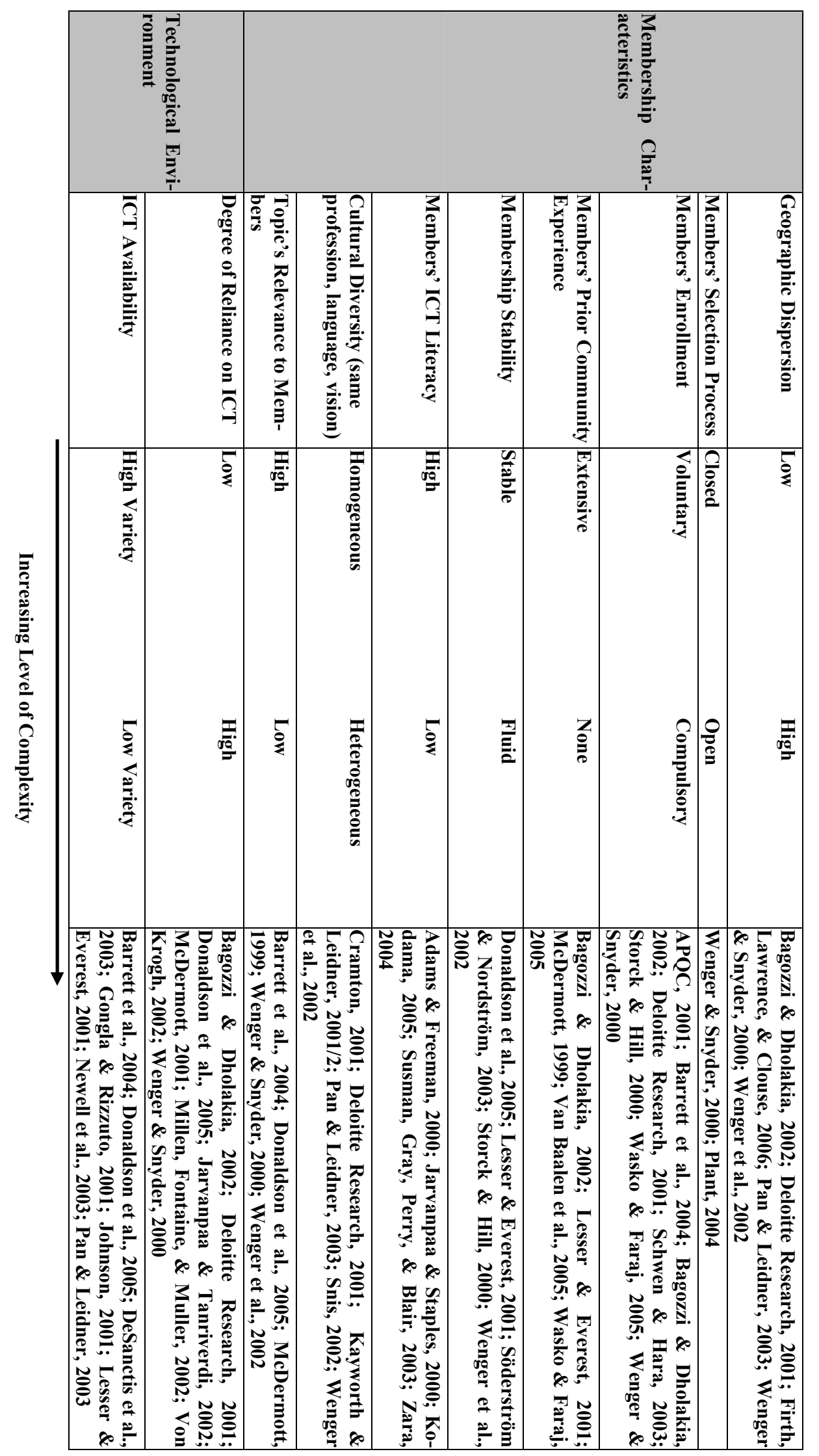




\section{Demographics}

\section{Orientation (operational $\leftrightarrow$ strategic)}

VCoPs may be created for different purposes; some have strategic implications while others are operational in nature (Denning, 1998). A strategic VCoP is created to support the overall mission and orientation of the organization; such VCoPs are created to shape the organization's response to an important environmental change or to define new products or segment markets. An operational VCoP, on the other hand, focuses on the daily operations of the organization, such as quick answers to customer problems. Be it strategic or operational, a $\mathrm{VCoP}$ has a greater chance at being launched and successfully developed if its mission is in line with the overall mission of the organization. A strategic VCoP, more likely to encounter high level of uncertainty and fuzziness, faces more challenges, particularly at its initiation.

\section{Life span (temporary $\leftrightarrow$ permanent)}

Life spans of CoPs vary widely (Wenger et al., 2002). While it may initially be indeterminate, a $\mathrm{VCoP}$ can be assembled on a temporary basis to accomplish a specific purpose (e.g., a response to an ad hoc environmental change), but is usually created on a permanent basis with no definite time frame in mind, as an on-going mechanism for information sharing. A temporary VCoP may undergo less difficulty, since a high level of energy may be invested for a rather short period of time and a narrow focus may help decrease the level of uncertainty surrounding its launching.

\section{Age (young $\leftrightarrow$ old) and level of maturity (transformation stage $\leftrightarrow$ po- tential stage)}

Age defines the period of time the $\mathrm{VCoP}$ had to experiment and to progress and varies from young (less than a year) to old (more than 5 years). Launching a new VCoP is more challenging, as assembling people, identifying common interests, choosing technology, developing norms and processes will prove difficult. A VCoP may also face some difficult challenges when, at the end of the cycle, it has to reinvent itself. Although there may be a correlation, age does not necessarily go hand in hand with maturity level. VCoPs go through different phases throughout their life. Several authors (e.g., Gongla \& Rizzuto, 2001; McDermott, 2000a; Wenger et al., 2002) have proposed CoP's evolution models. They all describe the same process, but differ in terms of the timing of their stages, the elements emphasized, and the vocabulary used. It is divided into five stages: (1) potential, (2) coalescing, (3) maturing, (4) stewardship, and (5) transformation, as defined in Table 2.

Table 2: Stages of community development (Wenger et al., 2002, p. 69)

\begin{tabular}{|l|l|}
\hline Stage & Definition \\
\hline Potential & $\begin{array}{l}\text { A loose network of people juggles with the idea of forming a CoP; structure, mem- } \\
\text { bers, and common interests are identified, selected, and agreed upon. }\end{array}$ \\
\hline Coalescing & $\begin{array}{l}\text { The CoP is officially launched. The CoP activities are starting. The main focus is } \\
\text { on establishing value. }\end{array}$ \\
\hline Maturing & $\begin{array}{l}\text { The CoP develops a stronger sense of itself. While its core practice is better de- } \\
\text { fined, members see gaps and develop new areas of knowledge. The CoP goes from } \\
\text { sharing tips to developing a comprehensive body of knowledge. Members know } \\
\text { each other; a level of trust has developed. }\end{array}$ \\
\hline
\end{tabular}




\begin{tabular}{|l|l|}
\hline Stewardship & $\begin{array}{l}\text { The CoP goes through a stage where the biggest challenge is to sustain its momen- } \\
\text { tum. }\end{array}$ \\
\hline Transformation & $\begin{array}{l}\text { An event - a major change in practice or work organization, a large influx of new } \\
\text { members, a leadership change, or a high decrease in energy level - will trigger the } \\
\text { need for renewal. The CoP may start all over again on a new basis or simply fade } \\
\text { away and die. }\end{array}$ \\
\hline
\end{tabular}

While it is expected that a VCoP will progress and reach a higher level of maturity, some VCoPs take more time than others to evolve; they may stall at one phase or progress rapidly to a high level of maturity (Gongla \& Rizzuto, 2001; Wenger et al., 2002). Identifying the phase a VCoP is in may help explain its specific challenges and issues, and the decisions and actions that are needed to lead it to success.

\section{Organizational Context}

\section{Creation process (spontaneous $\leftrightarrow$ intentional)}

CoPs have existed for ages, born from people's spontaneous desire to group, share ideas, help, and be helped (McDermott, 1999). However, as part of a knowledge management strategy, top management may want to launch a CoP; henceforth, a CoP can be deliberately established by management who will define its purpose and select key members (top-down approach) or be spontaneously emerging and created by a number of interested members (bottom-up approach) (Fontaine, 2001). Between these two extremes, management can take charge of a CoP that was first initiated by a handful of interested members, or more or less directly decide to recognize and support an existing information network (Barrett et al., 2004; Gongla \& Rizzuto, 2001; McDermott \& O'Dell, 2001; Swan et al., 2002; Wenger \& Snyder, 2000). As commented by Schwen \& Hara (2003), sharing and learning however cannot be "legislated into existence." An intentionally created VCoP may therefore encounter more difficulties than a spontaneously formed one; fostering and sustaining members' interest may require greater effort.

\section{Boundary crossing (low $\leftrightarrow$ high)}

VCoPs are often created to break organizational silos and promote collaboration, learning, and information sharing. Usually based on "practice- and person-based networks" (Pan \& Leidner, 2003), their membership commonly crosses boundaries across work groups, organizational units and even organizations (Wenger \& Snyder, 2000). Boundary crossing can be considered low if only similar work group members are involved, medium if different groups or units from the same organization are part of the community, and high if members of different organizations are involved in a VCoP (Wenger et al., 2002). A high level of boundary crossing may make it more difficult to develop an adequate level of trust and to buy into the idea of sharing knowledge (Wenger et al., 2002).

\section{Environment (facilitating $\leftrightarrow$ obstructive)}

Forces from the larger organizational context in which the CoP exists may shape its very existence, the challenges it faces, and its outcomes (McDermott \& O'Dell, 2001). This context includes the economic environment, the culture and subcultures of the organization involved, the management style, and the political context. All these dimensions interact to create an environment that is facilitating, neutral, or obstructive to the creation and development of the CoP (Cothrel \& Williams, 1999). In terms of economic environment, CoPs tend to be more active in industries where turbulence and rapid change are common (Barrett et al., 2004; Cothrel \& Wil- 
liams, 1999), increasing the need for information and knowledge. When assumptions and beliefs are challenged, external knowledge is used as a fuel for experimentation, intense debate is encouraged, and high levels of participation are expected in managing knowledge, which creates an adequate culture for supporting the creation and distribution of knowledge (De Long \& Farey, 2000). Bureaucracies that depend on stability to function may prove incompatible with a somewhat unpredictable knowledge sharing mechanism such as a VCoP. The global evaluation of the environment must therefore consider all opposing forces, especially in a multi-organization environment. The launching of a $\mathrm{CoP}$ is more likely to be successful in an organization that designs the CoP in accordance with its culture and its environment (McDermott \& O’Dell, 2001).

\section{Organizational slack (high $\leftrightarrow$ low)}

Managing the implementation of a $\mathrm{VCoP}$ implies the management of organizational change and learning. Occurring at the individual, group and organizational levels, learning is the result of a series of complex processes (Marquardt, 1999), which require time and an intensive support system. To be able to sustain VCoPs successfully and to absorb the costs associated with the nonproductive phases inherent to the learning curve, an organization must have some form of organizational slack (Romanelli \& Tushman, 1994), i.e., the general availability of tangible and intangible resources in the wide-ranging system into which a VCoP is created. A system with a high availability of resources is more likely to promote experimentation and support new VCoPs. When organizational slack is low, VCoPs may receive less support and resources.

\section{Degree of institutionalized formalism (unrecognized $\leftrightarrow$ institutional- ized)}

The relationship between a CoP and an organization may take several forms (Wenger et al., 2002). The degree of institutionalized formalism relates to the degree to which a CoP has been integrated into the formal structure of an organization. Wenger et al. (2002, p. 28) define the continuum as going from unrecognized (invisible to organization), bootlegged (visible only to a group), legitimized (officially sanctioned), supported (receiving direct resources) to institutionalized (official status and functions). An institutionalized $\mathrm{CoP}$ is fully integrated and considered a formal unit of the organization; an "unrecognized" $\mathrm{VCoP}$ has no acknowledged existence in the organization. Going up on the institutionalism continuum provides the CoP with legitimacy and funding (APQC, 2001).

\section{Leadership (clearly assigned $\leftrightarrow$ continuously negotiated)}

A leadership structure can be designed in the initial lay out of a VCoP. An organization can either create a formal $\mathrm{CoP}$ governance structure where individuals are appointed to specific roles (Gongla \& Rizzuto, 2001; Lesser \& Everest, 2001) or leave roles and authority relationships to emerge through interaction around expertise (Lesser \& Storck, 2001). In clearly assigned leadership, roles are established and assigned to specific people by the VCoP's members and/or by management. In a continuously negotiated leadership, responsibilities and roles are in a permanent state of flux, negotiated and established as needs are identified. Clearly assigned roles may become increasingly important as the CoP grows in size and importance (Fontaine, 2001). They may lead to engagement and accountability, and help people legitimize time spent working on the VCoP. 


\section{Membership Characteristics}

\section{Size (small $\leftrightarrow$ large)}

Size refers to the number of members involved in a VCoP. This number may be small and intimate (only a few people) to very large (more than a thousand people) (Wenger et al., 2002). A $\mathrm{CoP}$ is usually constituted of a core group of members who provide intellectual and social leadership (Wenger \& Snyder, 2000), and peripheral members, who often get great value from their lurking activity (McDermott, 2001). But size does matter, a large community is more likely to include people with contingent, diverse, and distributed interests, and social relationships may become ephemeral (Von Krogh, 2002). As a result, it may be more challenging to meet the needs of all members (Mitchell, 2002) and to find valuable information among the mass of available material (Wasko \& Faraj, 2000). In a large CoP, the marginal contribution of each member is lessened and the rational, self-interested individual may choose to free ride (Von Krogh, 2002). Hence, very large CoPs are usually structured into subgroups (by topic or region) to encourage active participation (Wenger et al., 2002).

\section{Geographic dispersion (low $\leftrightarrow$ high)}

Geographic dispersion refers to the physical location of the participants. Advances in ICT have made collaborating through time and distance possible (Wenger et al., 2002). Members of a VCoP may all be physically located in the same building (low dispersion) or scattered around the world (high dispersion). Throughout a province or state, the dispersion could be considered to be medium to low and, throughout a large country such as Canada or the USA, the level could be qualified as medium to high. A high level of dispersion brings about additional challenges. Physical distance encourages psychological distance; it takes more intentional participation efforts from members and from the VCoP's leader to keep the community alive (Wenger et al., 2002). In such a context, it also becomes more complicated and expensive for members to participate in regular, face-to-face meetings. High geographic dispersion means that members are in different time zones, making synchronous communications all the more difficult. High geographic dispersion is also likely to increase the cultural diversity of a VCoP.

\section{Members' selection process (closed $\leftrightarrow$ open)}

VCoPs may use different methods to select their members (Plant, 2004; Wenger \& Snyder, 2000). An on-line community usually has an open membership whereby anyone who has access to a computer and an Internet connection can become a member and participate (e.g., an Internet community). In our case, a VCoP with an open membership means that anyone in the organization who is interested can become a member. A VCoP may also choose to have a closed membership and to admit only people who meet a predetermined list of criteria. In addition to having better control over its size, a closed-membership VCoP has more control over the characteristics of its members, making managing, identifying common interests, and meeting easier. An openmembership VCoP, however, may be more in line with the idea of organization-wide knowledge sharing. In an open-membership VCoP, lurkers may learn interesting things that will prove useful in the long run, while their status, at the time, may not have allowed them to become members, had the VCoP had a closed-membership policy.

\section{Members' enrollment (voluntary $\leftrightarrow$ compulsory)}

Members' enrollment can take many forms, from voluntary to strongly encouraged, to compulsory (APQC, 2001). More generally, potential candidates go through a self-selection process, as- 
sessing what they can gain from their participation and what their contributions might be; if the resulting evaluation is positive, they will then volunteer to be part of a community. A member's participation can also be "strongly" encouraged by management to the point where the potential member does not feel free to turn down the offer. Volunteers are generally more motivated than conscripted members (Deloitte Research, 2001; Mitchell, 2002). Compulsory participation is more likely to be found when management builds the $\mathrm{CoP}$ in a top-down approach and may have unintended negative impacts (Schwen \& Hara, 2003). A CoP where members are mainly conscripted is likely to encounter legitimacy problems since, although enrollment can be "forced," monitoring or measuring meaningful participation may prove very difficult. This characteristic is evaluated on a continuum since a $\mathrm{CoP}$ may be comprised of a mix of voluntary and drafted members.

\section{Members' prior community experience (extensive $\leftrightarrow$ none)}

An existing network of individuals may be the instigator of a new CoP (Lesser \& Everest, 2001) or management can build on an existing network as a basis for a new CoP (McDermott, 1999). In such a case, members already know each other and are used to collaborating and sharing information among themselves. "A system of cues makes possible a deep improvisation of knowledge sharing, where people send and interpret cues as to when, where, and how knowledge sharing is appropriate" (Von Krogh, 2002, p. 92). Prior community experience may vary from extensive (when the community is based on an existing network), to medium (when members of the community have worked in groups, although those groups may not be identical to the VCoP), to low and none. Moving an existing community from exclusively face-to-face meetings to the virtual world can meet two opposing forces: (1) members may resist the new technological arrangement and may want to go back to their previous successful way and/or (2) previous community experience may remove the uncertainty that members of a new community must cope with, easing the passage from a face-to-face to a virtual environment. Despite possible drawbacks, an experienced group has an advantage over a newly created CoP. While some resistance may be encountered, the group already has a purpose, some legitimacy, established roles and defined norms, easing the passage to the development of a real virtual community.

\section{Membership stability (stable $\leftrightarrow$ fluid)}

A VCoP may have permanent members (i.e., a stable membership), but can also have changing membership, ranging from moderately stable to fluid. Through normal organizational turnover, membership may change over time (Storck \& Hill, 2000). An open VCoP may experience less stability than a closed one. Stability may also be affected if key actors of the VCoP are replaced by new members. In which case, a complete socialization and sense-making process is triggered. The values, norms, and communication patterns of the new member will be confronted with the ones that were adopted by the VCoP. A learning and adaptation process on both sides then occurs and is more or less successful depending on the adaptive capacity of the parties involved. If new members join repeatedly and participate extensively, considerable energy will have to be devoted to this adaptation process. A sudden and important influx of new members can challenge the actual CoP and call for a radical transformation (Wenger et al., 2002).

\section{Members' ICT literacy (high $\leftrightarrow$ low)}

A VCoP exists mainly through ICT-mediated interactions; the characteristics of this technological environment will be discussed in the next sub-section. At the member's level, however, it is important to consider the level of comfort members feel towards the use of ICT. In a single VCoP, there can be wide discrepancies in the members' technological proficiency, i.e., in their ability to 
use the technology efficiently. Some members might be comfortable working with groupware, whiteboards, and videoconferencing, while others might need to be taught how to attach a file to an e-mail message. A lack of experience with ICT may make it difficult for some members to participate to their full potential because of the barriers created by technology (Jarvanpaa \& Staples, 2000). They may even be looked down upon by members who master the technology. These inexperienced members may be afraid to answer general inquiries or to participate in on-line discussions (Deloitte Research, 2001). They may also rely on traditional media such as the phone and the fax instead of more appropriate and sophisticated ICT, perpetuating one-on-one exchanges and potentially depriving others of important information. Thus, while a variety of ICT may be available, members' ability to use them appropriately and efficiently will facilitate or hinder participation and information sharing. While the level of ICT proficiency is an individual characteristic, a global assessment should be performed on the VCoP as a group. In a case where only a few members are inexperienced ICT users, knowledge transfer and support can easily be obtained from the group. In cases where most members are inexperienced, actions need to be taken for the group to be able to interact efficiently through ICT.

\section{Cultural diversity (homogeneous $\leftrightarrow$ heterogeneous)}

When evaluating a CoP, three levels of cultural influence must be considered: national, organizational, and professional (Wenger et al., 2002). First, cultural diversity in a VCoP may be created by mixing different national cultures. Hofstede (1993) shows how different cultures have different conceptualizations of management, leadership, autonomy, priority and focus, decisionmaking, and relationships between people. Furthermore, a variety of national cultures often comes with a diversity of languages, amplifying problems of communication and collaboration, and increasing the likelihood of people resisting participation (Pan \& Leidner, 2003). Second, a community of practice may bring together different organizational cultures, with different learning and adaptation processes (Hesselbein \& Johnston, 2002) as well as diverse knowledge sharing behaviors, evaluation and compensation systems, employees' expectations and preferences. The third dimension of culture is the integration of dissimilar professional cultures into a single VCoP. Influenced by education and professional associations, members of a specific professional culture develop their own knowledge bases, language, specialized vocabulary, technical routines, workplace values and norms, and even dress code. Members of different professional groups may thus exhibit differing mutual knowledge, expectations, assumptions and codes (Cramton, 2001).

Given the three levels of cultural influence, cultural diversity is evaluated on a continuum, whereby homogeneous describes a community in which members come either from the same organization or from organizations with similar cultures, are located in culturally close countries, and have similar professional backgrounds. At the other end of the continuum are VCoPs whose members have various professional backgrounds, come from disparate organizations, and are located in dissimilar national cultures. At the middle of this spectrum are VCoPs that may be qualified as displaying a medium cultural diversity.

While cultural heterogeneity is an asset that brings a rich variety of perspectives and experiences and provides a mechanism against groupthink, it can also make participating and sharing difficult (Pan \& Leidner, 2003). In addition to shaping how one relates to others and to the group (Wenger et al., 2002), culture defines what knowledge is, what is worth managing, who should possess it, and who should hoard it (De Long \& Fahey, 2000). People tend to interpret information based on their cultural filters leading to a potentially broad range of misinterpretations or distortions. Under these circumstances, it may be more challenging for the VCoP's members to identify and develop common interests and share a common understanding, to establish open communication and trust, delaying the time a VCoP requires to be effective. Norms need to be discussed, shared and nego- 
tiated (Wenger et al., 2002), and the VCoP leaders need to understand and manage the cultural tension (Deloitte Research, 2001) in order to change it into a creative energy.

\section{Topic's relevance to members (high $\leftrightarrow$ low)}

VCoPs are usually launched by organizations with a defined objective and theme in mind. This topic may be close to the daily work of its members or, on the opposite, be important for the organization, but far away from the members' day-to-day preoccupations. It is much simpler to foster a sense of engagement, develop commitment and create and uphold motivation when members focus on problems that are directly related to their work; they can see immediately the benefits of their participation (Wenger \& Snyder, 2000). Therefore, a topic should provide value to both the organization and the individuals (McDermott, 1999).

\section{Technological Environment}

\section{Degree of reliance on ICT (low $\leftrightarrow$ high)}

ICT allows VCoP members to leverage each other's knowledge in a timely fashion, without the constraints of time and space (McDermott, 2001; Von Krogh, 2002). While a VCoP needs to be predominantly using ICT to be called "virtual," VCoPs may be using technology to different degrees. One VCoP may use ICT $98 \%$ of the time and meet only once a year (high reliance on ICT), while another VCoP may use ICT extensively but meet three to six times a year (medium reliance on ICT), and yet another may meet face-to-face every month (low reliance on ICT). It is widely accepted that ICT will never be a perfect substitute for face-to-face encounters or meetings (Deloitte Research, 2001) and most VCoPs need some face-to-face time to be the most effective (Deloitte Research, 2001). Deprived of rich face-to-face contacts, especially at the beginning, a VCoP may have problems and/or take longer to establish a sense of identity and a common purpose, and to develop the shared knowledge that increases the likelihood of mutual understanding (Cramton, 2001). Most VCoPs need some face-to-face time to be the most effective (Deloitte Research, 2001) and the resulting stronger personal relationships seem to be essential to carry the group through extended periods of virtual communication (Hildreth et al., 2000).

\section{ICT availability (high variety $\leftrightarrow$ low variety)}

In addition to traditional media such as the telephone, fax, teleconference and e-mail, VCoPs vary widely in terms of the means that are available to them to interact. ICT can provide virtual spaces where people can meet and discuss synchronously or asynchronously, store documents, hold electronic presentations, etc. An array of "meeting opportunities" may lead to higher and richer participation and an overall better exchange of knowledge (Barrett et al., 2004). Media differ in terms of richness and some may be more suited to tasks or messages with differing levels of ambiguity and uncertainty (Daft, Lengel, \& Trevino, 1987). The technology available may also shape the objectives of the VCoP and its adopted processes (De Sanctis et al., 2003). A low variety would include a CoP that only has access to simple, one-functionality software; the variety would be qualified as medium in the case of a CoP using both a document management capacity and a discussion forum; on the other hand, a CoP with access to a wide variety of ICT such as synchronous and asynchronous discussions and document management, would be an example of a VCoP with a wide variety of available ICT. 


\section{The Typology in Action}

While it is impossible to formulate specific hypotheses at this early stage of knowledge development in this area, we globally propose that VCoPs having different structuring characteristics face different challenges. From our data, we selected three VCoPs to show how different they can be, and to illustrate how the challenges and dilemmas faced by their members and leaders differ, and are contingent upon a VCoP's set of characteristics. A brief description of each VCoP is presented, followed by a discussion of the challenges faced by each.

\section{VCoP A}

VCoP A was created with the intention of offering members a forum to share tacit knowledge, discuss, and build a repertoire of the best practices in their particular domain. Although this organization from the service sector had very little resources and no tradition of tacit knowledge sharing, management was strongly committed to developing and leading this VCoP to success and, hence, when problems were encountered, they were quickly solved. The organization's intentions were to create this community of practice as a pilot project, evaluate its success and its potential as a tacit knowledge sharing tool, and possibly use this experience to build other communities around other areas of professional expertise. Given this particular orientation, the VCoP was created through a top-down process, and not integrated into the organization's formal structure.

Although members of VCoP A were all professionals in the same area of expertise, their levels of experience varied greatly, because they were scattered throughout three states, worked for different employers, with different cultures and operating modes, and held very different positions. All members were volunteers, recruited through a countrywide public search; they did not know each other and had no community experience prior to this project. Due to the members' geographic dispersion, and to the lack of organizational slack, which made it impossible to support travel expenses, all interactions were conducted through ICT. This was done despite the fact that the members did not have very extensive experience with technology.

\section{VCoP B}

$\mathrm{VCoP} \mathrm{B}$ was intentionally created by the management of an organization in the private sector. Knowledge management, continuous improvement and workers' empowerment are among the values of this organization, creating a facilitating environment for a VCoP. The organization viewed VCoP B as a pilot project intended to evaluate whether such communities were appropriate tools for increasing collective learning among people, and to document and share best practices. Therefore, at the time the research project took place, the community was not integrated into the organizational structure and was thought of as an officially sanctioned experiment with a short life span.

Since most members of VCoP B worked in the same department of the same organization, the boundary crossing level was low. Members were mainly technicians and engineers with different areas of expertise (cultural diversity $=$ medium). Initially, managers recruited motivated volunteers to participate in the community, but they eventually enlarged their recruiting effort to encompass all the production workers and new recruits. Although the VCoP's members met face-toface on a regular basis, they interacted mainly through ICT. 


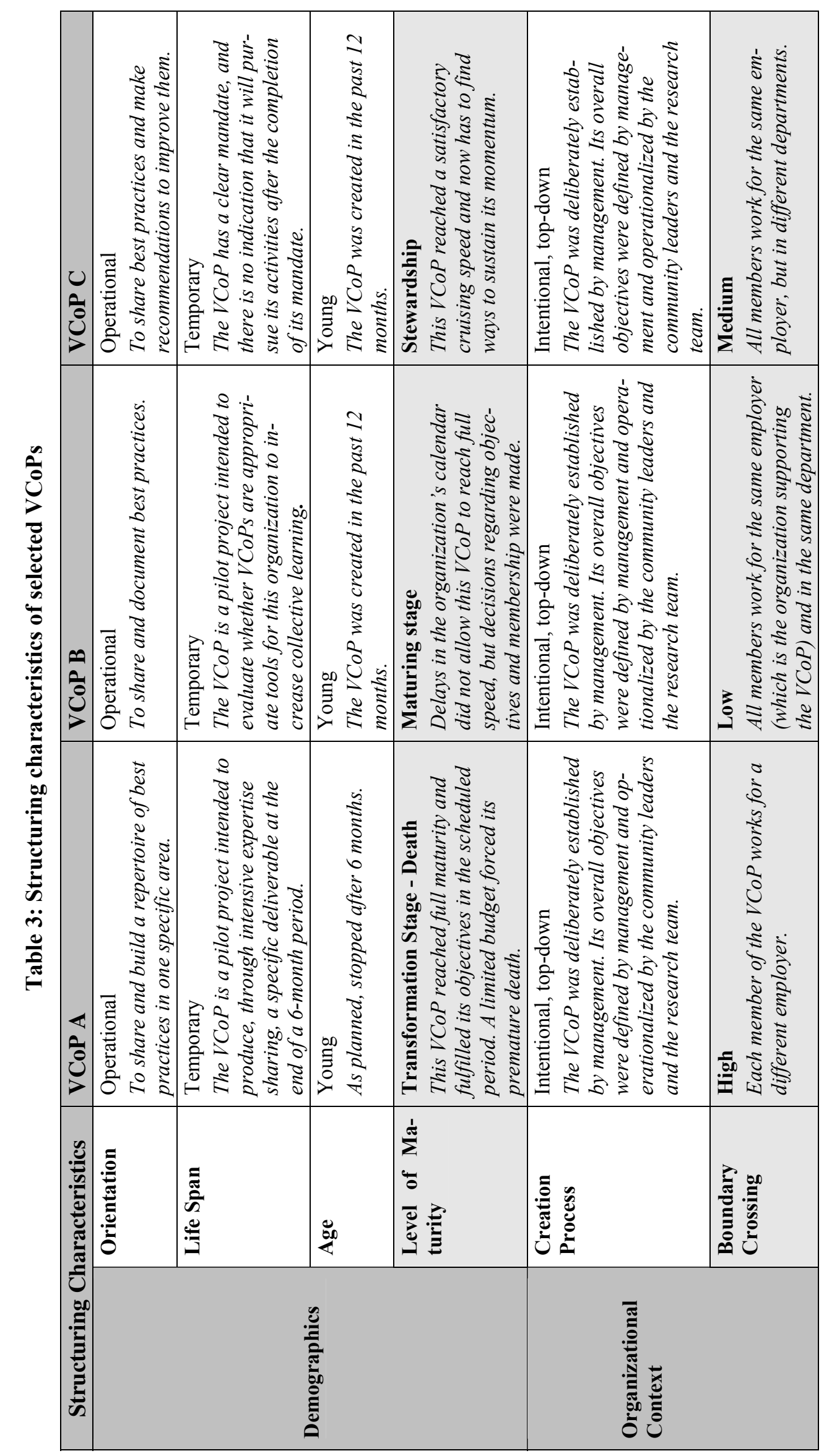




\begin{tabular}{|c|c|c|c|c|c|c|c|}
\hline \multirow[b]{2}{*}{ 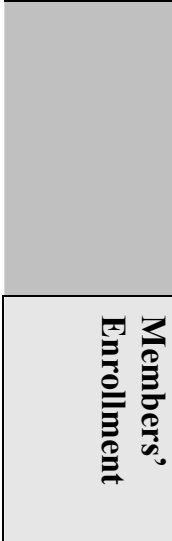 } & \multicolumn{3}{|c|}{ 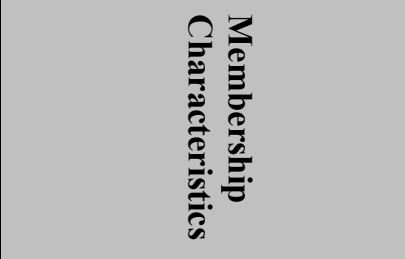 } & \multicolumn{4}{|c|}{ 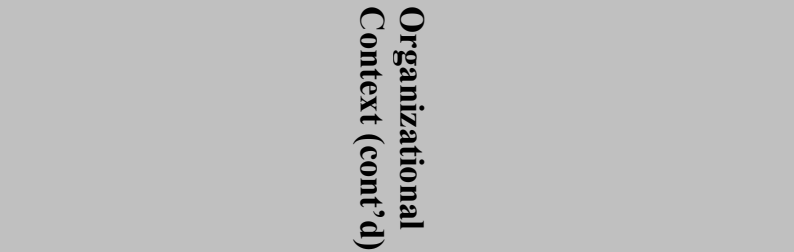 } \\
\hline & 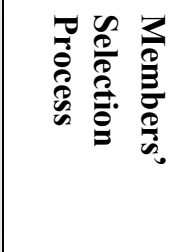 & 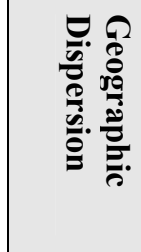 & $\stackrel{\mathscr{8}}{8}$ & 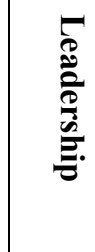 & 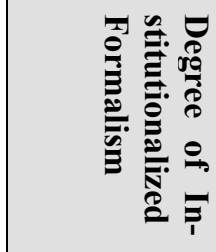 & 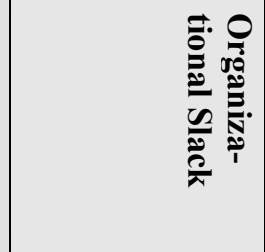 & \\
\hline 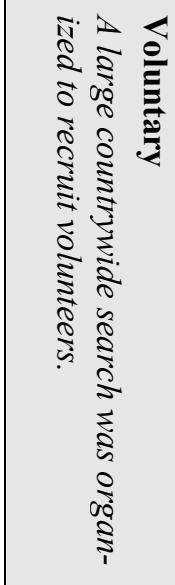 & 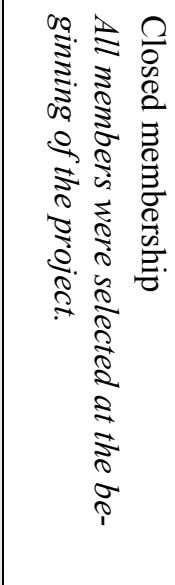 & 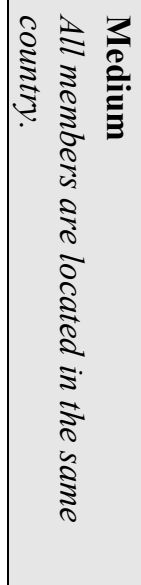 & 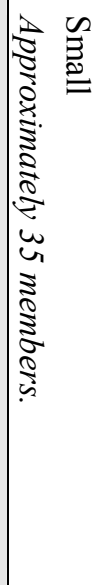 & 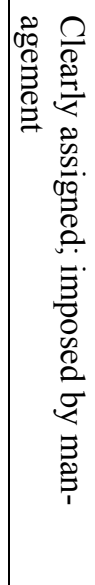 & 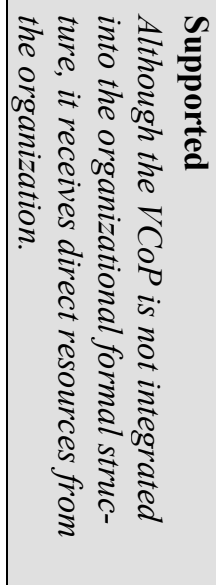 & 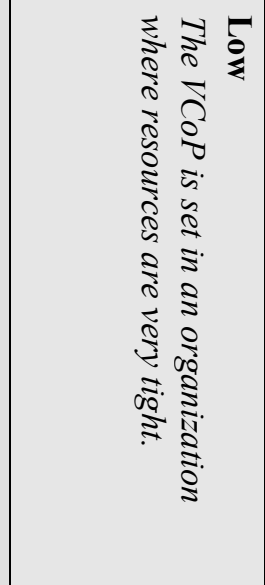 & 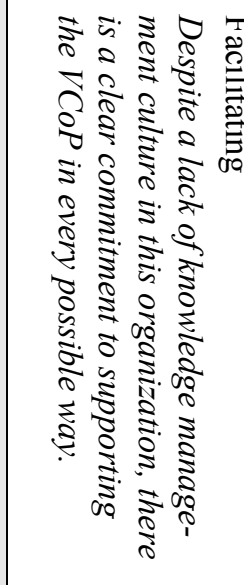 \\
\hline 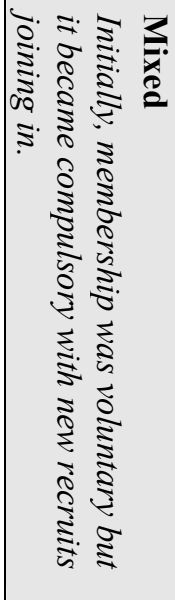 & 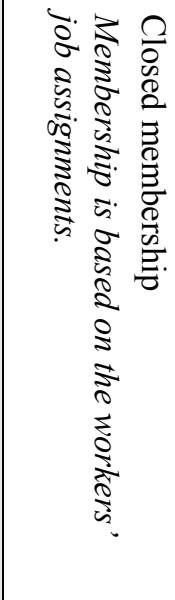 & 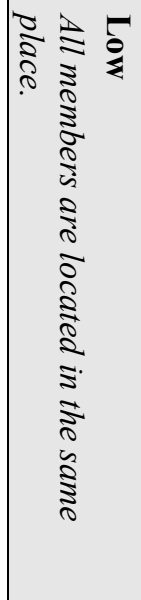 & 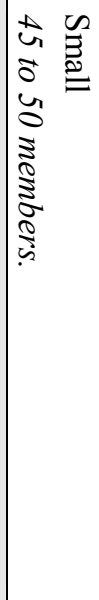 & 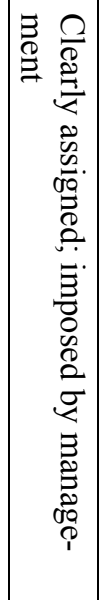 & 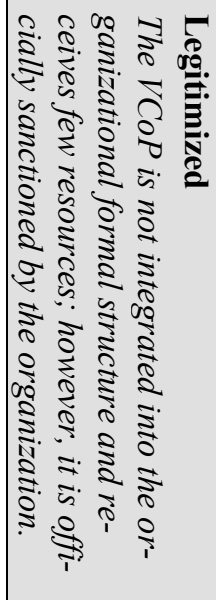 & 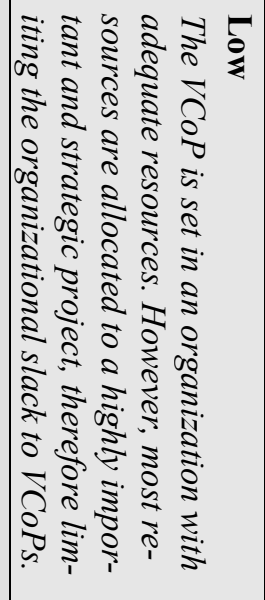 & 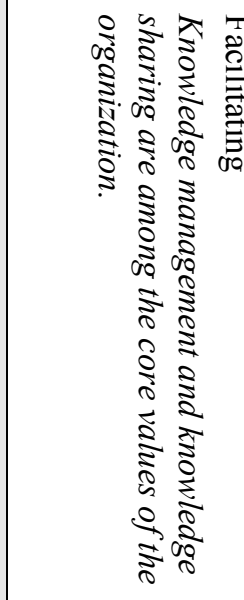 \\
\hline 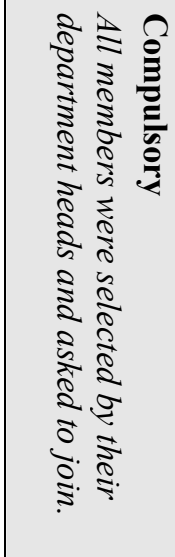 & 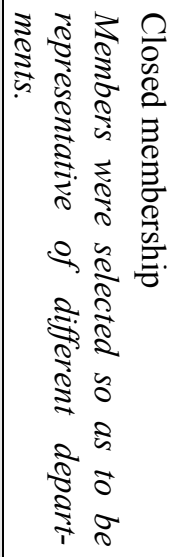 & 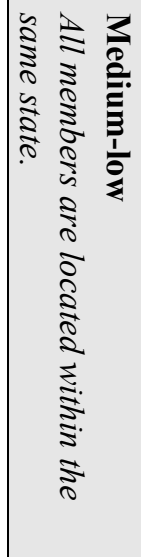 & 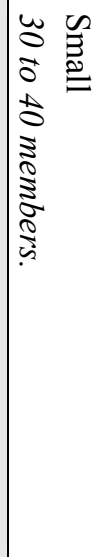 & 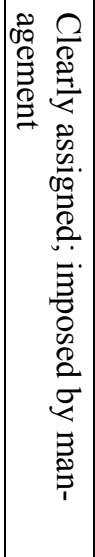 & 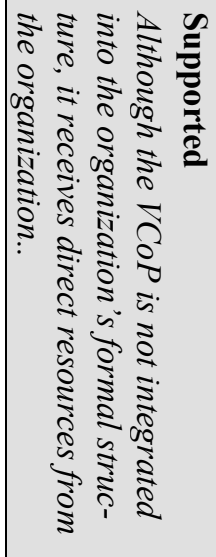 & 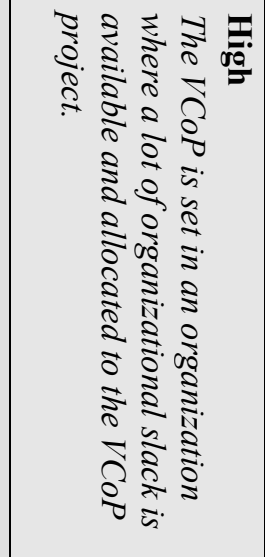 & 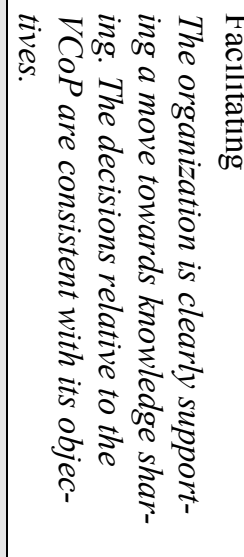 \\
\hline
\end{tabular}




\begin{tabular}{|c|c|c|c|c|c|c|}
\hline 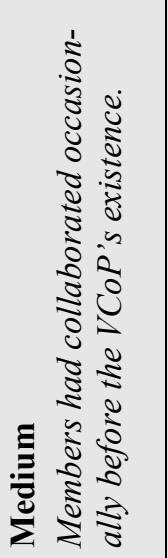 & 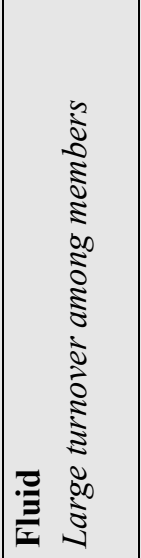 & 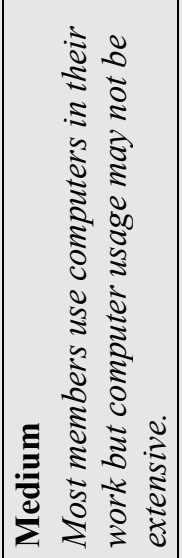 & 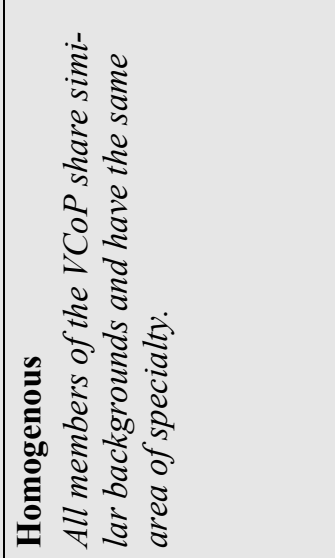 & 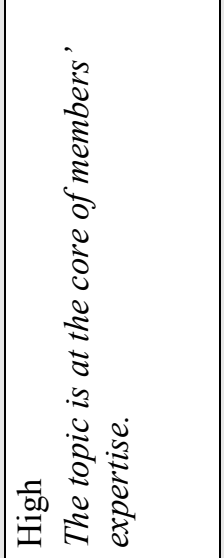 & 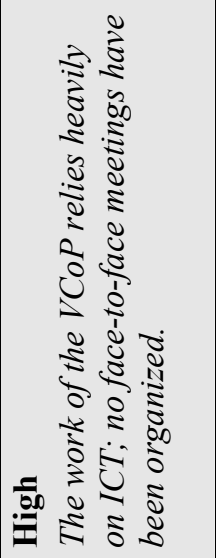 & 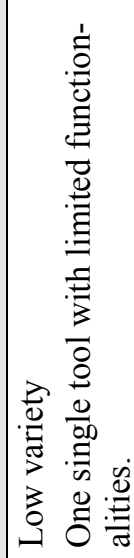 \\
\hline 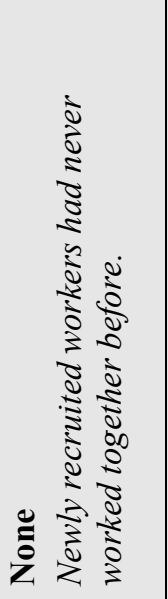 & 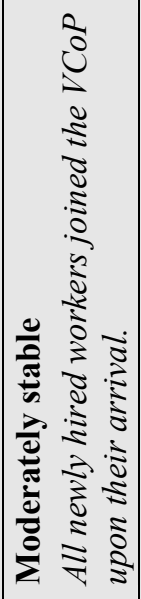 & 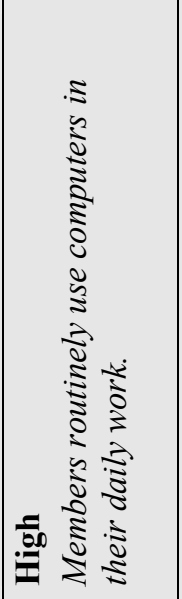 & 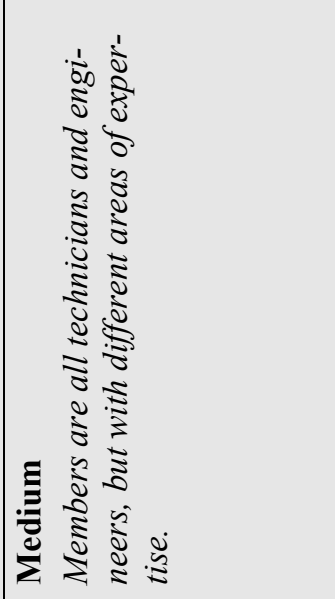 & 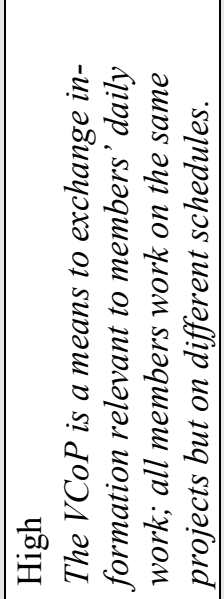 & 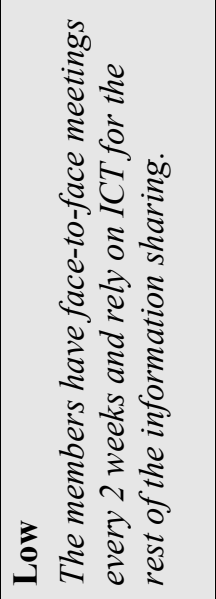 & 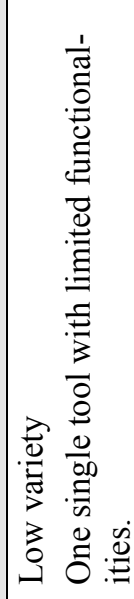 \\
\hline 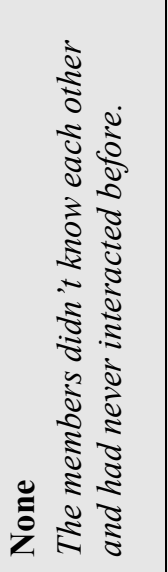 & 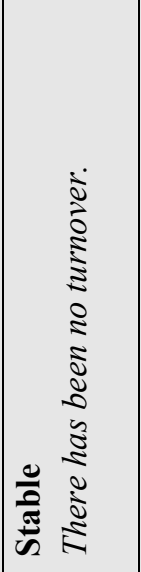 & 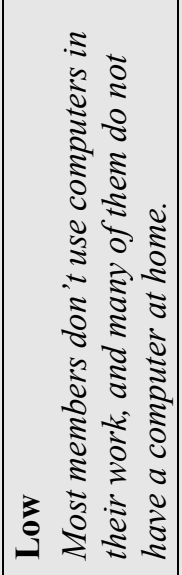 & 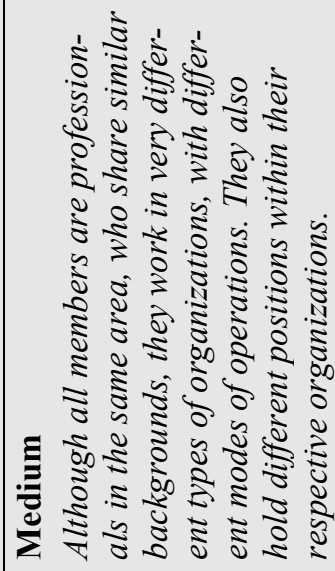 & 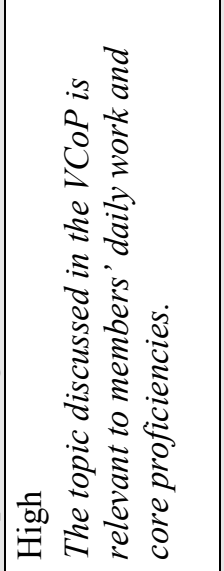 & 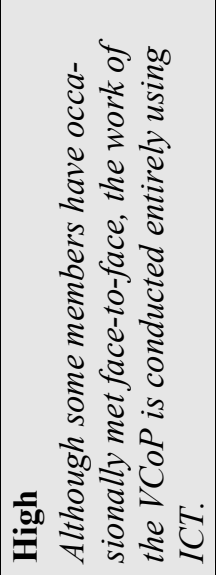 & 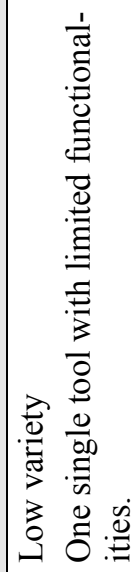 \\
\hline 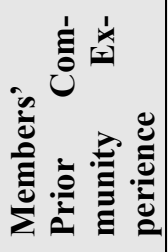 & 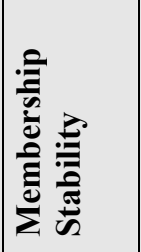 & 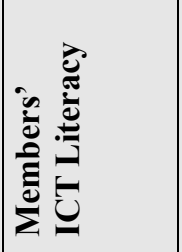 & 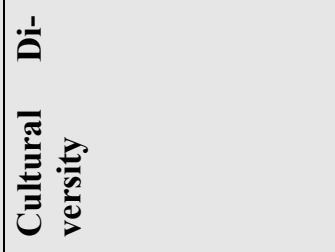 & 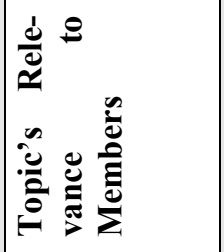 & 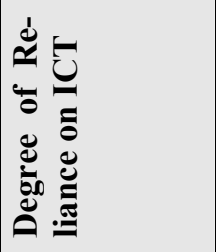 & 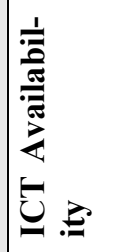 \\
\hline & & 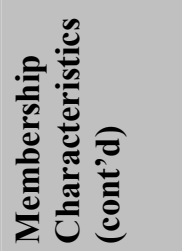 & & & \multicolumn{2}{|l|}{ 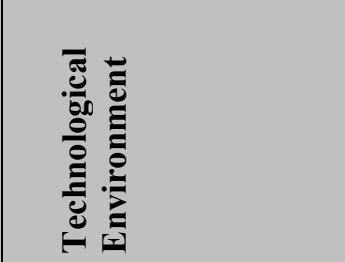 } \\
\hline
\end{tabular}




\section{VCOP C}

A large public-sector organization with a high level of resources is the home of VCoP C. This community was created by managers to fulfill a clear mandate: share best practices in order to (1) standardize them across decentralized departments, and (2) make recommendations for improvements. Despite this narrow focus and short life span, VCoP C was clearly established within an organization that strongly supported the move towards knowledge sharing and therefore allocated direct resources to the VCoP. Members of the community were all employees of the organization, although from various departments, with similar backgrounds and areas of specialty. They all worked in different regions of the same state, making geographic dispersion of the community average. Because members had occasionally collaborated before the creation of the community, their level of prior community experience was moderate.

All members were enrolled by their respective department heads, based on their expertise and the topic's relevance to their daily work. Despite this closed and forced membership, the community sustained a relatively high level of turnover, making the membership unstable. Due to their geographic dispersion, members relied heavily on technology and never met face-to-face.

The classification of these three VCoPs according to our typology is presented in Table 3. In this table, the structuring characteristics that vary from VCoP to VCoP are shaded.

\section{Different Characteristics Creating Different Challenges}

Although all these VCoPs were created in facilitating environments and had carefully chosen topics that were highly relevant to their members' daily professional practices, their other structuring characteristics differed, which raised, as will be discussed, various challenges.

While VCoP A reached maturity (level of maturity = transformation) and fulfilled its objectives according to schedule, despite resource scarcity (organizational slack $=$ low), VCoPs B and C struggled with their own development. An important issue for VCoP B, which had not yet reached full maturity (level of maturity = maturing), was whether it could move past the pilot stage and guarantee a long-term commitment of resources from the organization. Its challenge was directly related to the organizational slack. The organization had a costly and strategic project underway which consumed most of its resources, therefore diminishing its capacity to support other projects such as the $\mathrm{VCoP}$ (organizational slack = low). Set in a well-endowed organization (organizational slack $=$ high), $\mathrm{VCoP} \mathrm{C}$ was not concerned with its resources on a short term basis. However, it had reached a certain level of maturity (level of maturity $=$ stewardship) and its concern was the retention of members' interest and participation despite the fact that they no longer received the kind of attention they had been given as participants in a new experiment. Resources on a long term basis also needed to be negotiated. VCoP A, on the other hand, fulfilled its predefined objective, but was never allowed to go to the next phase. VCoP A was created in a relatively poor context - dependent on external government funding agencies to secure resources to finance this type of special project. This search for resources had not yet succeeded and therefore the next phase of this VCoP had been put on hold.

The three VCoPs were also different in terms of boundary crossing and member diversity. Both characteristics usually impact the level of cohesiveness within a community. On the one hand, $\mathrm{VCoP} A$ contained volunteers working for different employers, thus with very different working conditions and various expectations toward the community (boundary crossing $=$ high; cultural diversity $=$ medium). Some members did not have access to the electronic discussion forum used by the VCoP because their employers' firewalls which blocked it could not be bypassed. This 
technical problem brought much confusion and impeded the full participation of some members; creative solutions had to be found to include these people in the VCoP despite their initial inability to access the system. Four members of this $\mathrm{VCoP}$ were also given additional resources by their respective employers (either money, equipment, or time), while others did not receive anything. Therefore, the real-life experience of each member of this community was extremely diverse, making it more difficult to achieve a common vision and to build a high level of cohesiveness and engagement. However, despite this diversity, a high level of membership stability throughout the life of the community (membership = stable) allowed the participants to develop close relationships and build strong ties.

On the other hand, all members of VCoP B worked for the same company and therefore had similar working conditions (boundary crossing $=$ low) which facilitated communication and exchanges. The challenge regarding membership in this community arose from the fact that the members came from different backgrounds (cultural diversity = medium). The community leaders had to work at developing a common language, at finding topics and common ways to proceed, and at managing the members' different expectations in relation to the VCoP. In contrast, $\mathrm{VCoP} \mathrm{C}$ had a rather homogeneous cultural group (boundary crossing = medium; cultural diversity $=$ homogenous) composed of people from different departments from the same organization. Therefore, finding a common language and agreeing upon how to function was not a real challenge in this community.

In addition, contrary to $\mathrm{VCoP} \mathrm{A}, \mathrm{VCoPs} \mathrm{B}$ and $\mathrm{C}$ both had some members who had been forced to participate in the community (members' enrollment $=$ mixed for $\mathrm{VCoP} \mathrm{B}$ and compulsory for VCoP C). When a VCoP faces the challenge of integrating drafted members, the sense of purpose, engagement and participation may be much more difficult to achieve. Moreover, both VCoPs B and C had to continuously integrate new members who joined the community later in its life (membership stability = moderately stable for VCoP B, fluid for VCoP C). Under these circumstances, where topics, ways of doing, procedures, etc. are constantly negotiated, it may be more difficult for a $\mathrm{VCoP}$ to reach an effective level of trust and cohesiveness and attain its full speed. This is an accurate description of what happened to VCoP B. The uncertainty surrounding the end of their vital project was high since the final date was constantly postponed. New members were integrated into the VCoP, but not under the real conditions that would prevail once the strategic project had ended. As long as the project was underway, the VCoP could not attain its full speed. Without the proper conditions coming from the organizational context and a stabilized membership, despite an initial period of success, motivation remained difficult to sustain in this $\mathrm{VCoP}$, and it was much more difficult to reach a level of engagement and cohesiveness necessary for fruitful knowledge sharing.

The three communities described earlier also differed in terms of their degree of reliance on ICT, which may have had an impact on the level of cohesiveness, feeling of belonging, and sense of engagement of their members, overall affecting their levels of participation and satisfaction. Because $\mathrm{VCoPs} \mathrm{A}$ and $\mathrm{C}$ were geographically dispersed (geographical dispersion = medium for VCoP A and medium-low for VCoP C), their members had to communicate mostly through ICT (ICT reliance $=$ high); this contrasted with $\mathrm{VCoP} \mathrm{B}$, whose members were located in the same place (geographical dispersion $=$ low), and therefore met face-to-face on a regular basis (ICT reliance $=$ low). Ironically, this community had the most ICT literate members (ICT literacy $=$ high), whereas members from VCoP A had no or little experience with ICT use (ICT literacy $=$ low) and members from $\mathrm{VCoP} \mathrm{C}$ were moderately literate (ICT literacy = medium). Heavy reliance on ICT may be a burden on the community members, especially when they are not used to interacting with technology. Lack of competence, lack of self-confidence, and resistance to technology may impede members' participation in the community. The technological problems faced by VCoP A, as mentioned earlier, are another example of how heavy reliance on technology, especially in an 
environment that is not technology-friendly, may slow down the development of a community of practice. However, members' prior community experience may alleviate some of the difficulties brought about by technology. The members of two of the communities described here, VCoPs A and B, didn't know one another when the community started (prior experience $=$ none), while the members of VCoP C had some experience of working together (prior experience = medium). Prior community experience may enhance the support one will receive from peers when using ICT and, because a certain level of trust already exists, may create an atmosphere where people can experiment with ICT and make mistakes.

Due to their different sets of characteristics, each community faced various challenges and they responded to these difficulties in different manners. VCoP A clearly faced the challenge of managing geographical dispersion and heterogeneity of experiences in a context characterized by a lack of organizational slack. They tackled the problem in various ways. First, they found external resources (money) to build and support the community and to hire someone who would serve as a full-time community leader. Second, because the organization recognized that the success of the community depended upon its relevance to its members, the early stages of the community were used for the identification of a specific topic and the definition of a deliverable with which all participants could identify, because it was relevant to their daily practice. Third, the community leader recognized individual differences and had many one-on-one phone interactions with members, ensuring that each individual situation was acknowledged and taken into account.

VCoP B's challenge was to build both the credibility of this new mode of knowledge sharing, and the members' motivation to participate, in a context where participation was mostly mandatory and the long-term commitment of resources unclear. In an effort to build motivation to participate, the leader of the VCoP organized face-to-face meetings to build some cohesion and trust among members. This motivation building effort must continue to, for example, show how members may individually benefit from their participation in the community. However, in a context of low organizational slack, the problem of receiving resources remains. Without a clear commitment from the organization, the permanence of this community was not guaranteed.

As far as VCoP C was concerned, the launching phase was a success which could be attributed to the topic's high relevance to members and to the organization's supportive environment. However, the community then faced its toughest challenge: it had to sustain members' interest and participation when the initial honeymoon period was over. The organization faced this challenge by reinforcing the idea that a $\mathrm{VCoP}$ is a powerful tool for knowledge sharing.

Although this analysis draws from the individual experiences of only three communities of practice, it clearly shows that our typology helps in identifying the characteristics that differ among the various virtual communities of practice. Indeed, the three communities studied here, despite their similarities, clearly vary in accordance with some intrinsic structuring characteristics. The combinations of those characteristics make each VCoP unique. We have also shown that these structuring elements had an impact on the development and life of the three VCoPs. Being structurally different, these communities faced different challenges that had to be specifically addressed by their leaders and supporting organizations.

\section{Conclusion}

The main purpose of this article has been to further our understanding of virtual communities of practice. We have identified a typology that contains structuring characteristics on which such communities may vary and be compared, showing that not all VCoPs are similar, but that there are indeed differences. Using this typology to scrutinize three VCoPs, we have shown that diverse structuring characteristics lead to different strengths and challenges, which are best addressed by specific and contingent management practices. Although many authors have tried to identify a set 
of best practices to manage VCoPs (e.g., Lesser \& Everest, 2001; Wenger et al., 2002), our investigation clearly shows that, in order to ensure success, management decisions and actions have to be fine-tuned towards the unique personalities of their VCoPs.

Building this typology was a first step in the development of a finer understanding of VCoPs. To increase its external validity, future studies based on a larger number of communities should investigate how well the typology can be used to describe other sets of VCoPs. Testing and refining this typology will result in the development of a useful tool that should ultimately make it easier to compare empirical findings, to accumulate knowledge, and to formulate sound advice for practitioners. Another important incremental step will be to cluster the VCoPs into generic types leading to the identification of different configurations of VCoPs. Future research will then be able to analyze the challenges that specific configurations of VCoPs are more likely to face and investigate the management decisions/actions that can be taken to assure the VCoP's success in view of a particular configuration. In our view, such a contingent perspective in looking at VCoPs is extremely relevant and much more promising, both from a research and a practical angle, than treating VCoPs as a uniform phenomenon.

\section{Acknowledgement}

CEFRIO (www.cefrio.qc.ca) and all participating organizations are gratefully acknowledged for providing financial support for this research. The authors also wish to thank their fellow researchers and research assistants working on this project. Finally, a special acknowledgement goes to Guy Paré for his contribution to a virtual team paper by Dubé \& Paré (2004) which was used as an inspiration for this paper.

\section{References}

Adams, E. C., \& Freeman C. (2000). Communities of practice: Bridging technology and knowledge assessment. Journal of Knowledge Management, 4(1), 38-44.

American Productivity \& Quality Center [APQC]. (2001). Building and sustaining communities of practice: Continuing success in knowledge management. Houston: Author.

Ardichvili, A., Page, V., \& Wenthling, T. (2003). Motivation and barriers to participation in virtual knowledge-sharing communities of practice. Journal of Knowledge Management, 7(1), 64-77.

Bagozzi, R. P., \& Dholakia, U. M. (2002). Intentional social action in virtual communities. Journal of Interactive Marketing, 16(2), 2-21.

Barrett, M., Cappleman, S., Shoib, G., \& Walsham, G. (2004). Learning in knowledge communities: Managing technology and context. European Management Journal, 22(1), 1-11.

Brown, J. S., \& Duguid, P. (1991). Organizational learning and communities-of-practice: Toward a unified view of working, learning, and innovation. Organization Science, 2(1), 40-57.

Brown, J. S., \& Duguid, P. (2001). Structure and spontaneity: Knowledge and organization. In I. Nonaka \& D. J. Teece, (Eds.), Managing industrial knowledge: Creation, transfer and utilization (chapter 2: pp.44-67). London: Sage.

Cothrel, J., \& Williams, R. L. (1999). On-line communities: helping them form and grow. Journal of Knowledge Management, 3(1), 54-60.

Cramton, C. D. (2001). The mutual knowledge problem and its consequences for dispersed collaboration. Organization Science, 12(3), 346-371.

Daft, R. L., Lengel, R. H., \& Trevino, L. K. (1987). Message equivocality, media selection, and manager performance: Implications for information systems. MIS Quarterly, 11(3), 355-366. 
Deloitte Research. (2001). Collaborative knowledge networks: Driving workforce performance through web-enabled communities. New York: Author.

De Long, D. W., \& Fahey, L. (2000). Diagnosing cultural barriers to knowledge management. Academy of Management Executive, 14(4), 113-127.

Denning, S. (1998). Building communities of practice. In Knowledge management: Lessons from the leading edge (pp.48-50). Houston: American Productivity \& Quality Center.

De Sanctis, G., Fayard, A.-L., Roach, M., \& Jiang, L. (2003). Learning in online forums. European Management Journal, 21(5), 565-577.

Donaldson, A., Lank, E., \& Maher, J. (2005). Connecting through communities: How a voluntary organization is influencing healthcare policy and practice. Journal of Change Management, 5(1), 71-86.

Dubé, L., Bourhis, A., \& Jacob, R. (2004). « Structuring spontaneity »: The impact of management practices on the success of intentionally formed virtual communities of practice (Cahier du GReSI no 04-20). HEC Montréal : GReSI. Available at http://gresi.hec.ca/cahier.asp

Dubé, L., Bourhis, A., \& Jacob, R. (2005). The impact of structural characteristics on the launching of intentionally formed virtual communities of practice. Journal of Organizational Change Management, Special Issue on Organizational Transformation and E-business, 18(2), 145-166.

Dubé, L., \& Paré, G. (2004). The multi-faceted nature of virtual teams. In D. Pauleen (Ed.), Virtual teams: Projects, protocols and processes (chapter 1; pp.1-39). Idea Group.

Fontaine, M. (2001). Keeping communities of practice afloat. Knowledge Management Review, 4(4), 16021.

Firth, D. R., Lawrence, C., \& Clouse, S. F. (2006). Predicting internet-based online community size and time to peak membership using the Bass model of new product growth. Interdisciplinary Journal of Information, Knowledge, and Management, 1, 1-12. Retrieved March 24, 2006, from http://ijikm.org/Volume1/IJIKMv1p001-012_Firth01.pdf

Gongla, P., \& Rizzuto, C. R. (2001). Evolving communities of practice: IBM Global Services experience. IBM Systems Journal, 40(4), 842-862.

Hesselbein, F., \& Johnston, R. (Eds.). (2002). On leading change. San Francisco: Jossey-Bass.

Hildreth, P., Kimble, C., \& Wright, P. (2000). Communities of practice in the distributed international environment. Journal of Knowledge Management, 4(1), 27-38.

Hofstede, G. (1993). Cultural constraints in management theories. Academy of Management Executive, 7(1), 81-94.

Jarvanpaa, S. L., \& Staples, D. S. (2000). The use of collaborative electronic media for information sharing: An exploratory study of determinants. Journal of Strategic Information Systems, 9, 129-154.

Jarvanpaa, S. L., \& Tanriverdi, H. (2002). Leading virtual knowledge networks. Organizational Dynamics, 31(4), 403-412.

Johnson, C. M. (2001). A survey of current research on online communities of practice. Internet and Higher Education, 4, 45-60.

Kautz, K., \& Mahnke, V. (2003). Value creation through IT-supported knowledge management? The utilisation of a knowledge management system in a global consulting company. Informing Science, 6, 7588. Retrieved March, 24, 2006, from http://inform.nu/Articles/Vol6/v6p075-088.pdf

Kayworth, T. R., \& Leidner, D. E. (2001/2). Leadership effectiveness in global virtual teams. Journal of Management Information Systems, 18(3), 7-40.

Kodama, M. (2005). New knowledge creation through leadership-based strategic community - a case of new product development in IT and multimedia business fields. Technovation, 25, 895-908. 
Leonard-Barton, D. (1995). Wellspring of knowledge: building and sustaining the sources of innovation. Boston: Harvard Business School Press.

Lesser, E., \& Everest, K. (2001, March-April). Using communities of practice to manage intellectual capital. Ivey Business Journal, 37-41.

Lesser, E., \& Prusack, L. (1999). Communities of practice, social capital and organizational knowledge. Information Systems Review, 1(1), 3-10.

Lesser, E. \& Storck, J. (2001). Communities of practice and organizational performance. IBM Systems Journal, 40(4), 831-841.

Marquart, M. L. (1999). Action learning in action. Palo Alto: Davies-Black Publishing.

McDermott, R. (1999). Why information technology inspired but cannot deliver knowledge management. California Management Review, 41(4), 103-117.

McDermott, R. (2000a). Community development as a natural step. Knowledge Management Review, 3(5), 16-19.

McDermott, R. (2000b). Planned spontaneity. Knowledge Management Review, 3(4), 5.

McDermott, R. (2001). Knowing in community: 10 critical success factors in building communities of rractice. Retrieved June 23, 2005, from http://www.co-i-l.com/coil/knowledge-garden/cop/knowing.shtml

McDermott, R., \& O’Dell, C. (2001). Overcoming cultural barriers to sharing knowledge. Journal of Knowledge Management, 5(1), 76-85.

Millen, D. R., Fontaine, M. A., \& Muller, M. J. (2002). Understanding the benefit and costs of communities of practice. Communications of the ACM, 45(4), 69-73.

Miller, D., \& Whitney, J. O. (1999). Configuration as a pillar of competitive advantage. Business Horizons, $42(3), 5$.

Mitchell, J. (2002). The potential for communities of practice to underpin the National Training Framework. Retrieved June 23, 2005, from the John Mitchell \& Ass Web site: http://www.reframingthefuture.net/publications_4.html

Muller, M. J. (2002). Patterns of participation in two communities of practice: Communities of engagement vs. community of reference. Retrieved June 23, 2005, from the IBM Research Center Web site: http://domino.research.ibm.com/cambridge/research.nsf/0/6a6879a65d997f3f85256c24005792de/\$FIL E/TR2002-03.pdf

Newell, S., Galliers, R. D., \& Huang, J. C. (2003). Conceptualizing the three dimentsions of interorganizational communities of practice. In C.U. Ciborra, R. Mercurio, M. de Marco, M. Martinez, \& A. Carignani (Eds.), Proceedings of the Eleventh European Conference on Information Systems. Naples, Italy. Available from http://is2.lse.ac.uk/asp/aspecis/Default.htm

Nonaka I., \& Takeuchi, H. (1995). The knowledge-creating company. New York: Oxford Press.

Pan, S. L., \& Leidner, D. E. (2003). Bridging communities of practice with information technology in pursuit of global knowledge sharing. Journal of Strategic Information Systems, 12(1), 71-88.

Plant, R. (2004). Online communities. Technology in Society, 26, 51-65.

Romanelli, E., \& Tushman, N. L. (1994). Organizational transformation as punctuated equilibrium: an empirical test. Academy of Management Journal, 37(5), 1141-1166.

Santos, J., Doz, Y., \& Williamson, P. (2004). Is your innovation process global? Sloan Management Review, 45(4), 31-37.

Schwen, T. M., \& Hara, N. (2003). Community of practice: A metaphor for online design? The Information Society, 19, 257-270. 
Snis, U. L. (2002). Challenges for knowledge communities in technical work domains. In S. Wrycza (Ed.), Proceedings of the Tenth European Conference on Information Systems. Gdansk, Poland. Available from http://is2.lse.ac.uk/asp/aspecis/Default.htm

Söderström, M., \& Nordström, T. (2003). Regional IS knowledge networks: Elaborating the theme of relevance of IS research. Informing Science, 6, 49-59. Retrieved March, 24, 2006, from http://inform.nu/Articles/Vol6/v6p049-059.pdf

Storck, J., \& Hill, P. A. (2000, Winter). Knowledge diffusion through "strategic communities". Sloan Management Review, 63-74.

Susman, G. I., Gray, B. L., Perry, J., \& Blair, C. E. (2003). Recognition and reconciliation of differences in interpretation of misalignements when collaborative technologies are introduced into new product development teams. Journal of Engineering and Technology Management, 20, 141-159.

Swan, J., Scarbrough, H., \& Robertson, M. (2002). The construction of "communities of practice" in the management of innovation. Management Learning, 33(4), 477-496.

Thompson, M. (2005). Structural and epistemic parameters in communities of practice. Organization Science, 16(2), 151-164.

Thornhill, S. (in press). Knowledge, innovation and firm performance in high- and low technology regimes. Journal of Business Venturing.

Van Baalen, P., Bloemhof-Ruwaard, J. \& Van Heck, E. (2005). Knowledge sharing in an emerging network of practice: The role of a knowledge portal. European Management Journal, 23(3), 300-314.

Von Krogh, G. (2002). The communal resource and information systems. Journal of Strategic Information Systems, 11, 85-107.

Warda, J., \& Zieminski, J. (2000). Collaborating for innovation. Second annual innovation report. The Conference Board of Canada. $39 \mathrm{p}$.

Wasko, M. M., \& Faraj, S. (2000). "It is what one does": why people participate and help others in electronic communities of practice. Journal of Strategic Information Systems, 9, 155-173.

Wasko, M. M., \& Faraj, S. (2005). Why should I share? Examining social capital and knowledge contribution in electronic communities of practice. MIS Quarterly, 29(1), 35-57.

Wenger, E. (2001, March). Supporting communities of practice : A survey of community orientedtechnologies. Retrieved September 23, 2001, from http://www.ewenger.com/tech/index.htm

Wenger, E., McDermott, R., \& Snyder, W. M. (2002). Cultivating communities of practice. Boston: Harvard Business School Press.

Wenger, E. C., \& Snyder, W. M. (2000, Jan-Feb). Communities of practice: The organizational frontier. Harvard Business Review, 139-145.

Yap, L. X., \& Bock, G.-W. (2005). An empirical investigation of the effects of size on strength of relationship and commitment in a virtual community. In D. Bartmann, F. Rajola, J. Kallinikos, D. Avison, R. Winter, P. Ein-Dor, J. Becker, F. Bodendorf \& C. Weinhardt, (Eds.), Proceedings of the Thirteenth European Conference on Information Systems. Regensburg, Germany. Available from http://is2.1se.ac.uk/asp/aspecis/Default.htm

Zara, O. (2004). Le management de l'intelligence collective: Vers une éthique de la collaboration [Managing the collective intelligence: Towards an ethic of collaboration]. Retrieved August 23, 2004, from http://www.axiopole.com/intelligence_collective.php 

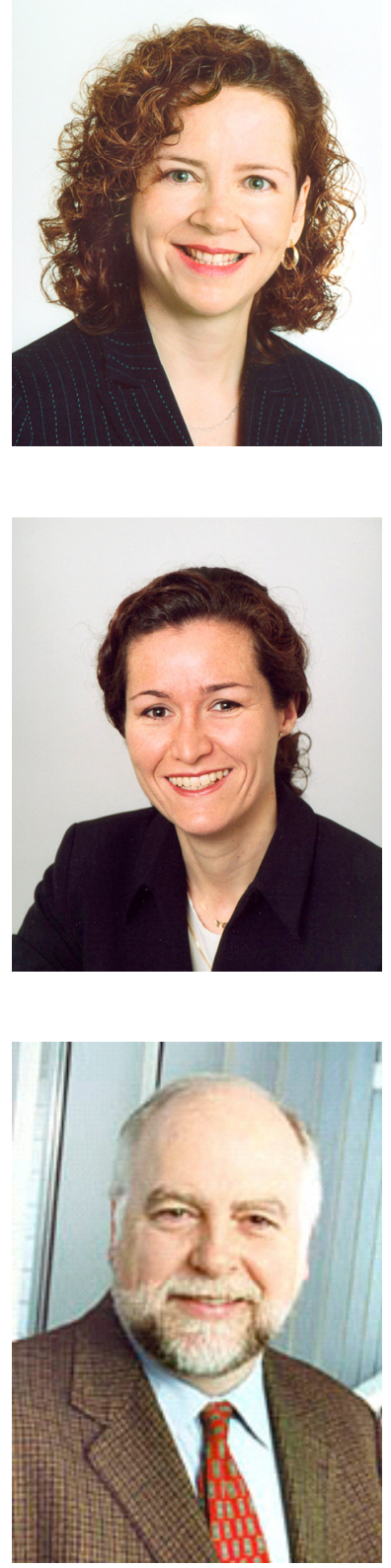

\section{Biographies}

Line Dubé is an associate professor in the Department of Information Technologies at HEC Montréal. She holds a Ph.D. in Management Information Systems from Florida International University. Her current research focuses on the transformation of work practices through the use of IT, knowledge management, qualitative research methods, and the management of small and medium technology firms. Her work has been published in a variety of journals, including MIS Quarterly, Communications of the ACM, Accounting, Management \& Information Technology, and Information Technology \& People, and presented at a number of national and international conferences.

Anne Bourhis is an associate professor in the Department of Human Resources Management at HEC Montréal and a research associate at the Centre francophone de recherche en informatisation des organisations (CEFRIO). She holds a Ph.D. in Organizational Behavior from the University of Illinois at Urbana-Champaign. Her research interests focus on staffing, organizational entry and organizational socialization, as well as knowledge management. Her work has been published in several journals, including Law and Human Behavior, Industrial Relations, the Journal of Organizational Behavior, the Journal of Applied Social Psychology, and the Journal of Applied Psychology.

Réal Jacob is Director of the Department of Management at HEC Montréal. He serves as Scientific Director of the Centre francophone de recherche en informatisation des organisations (CEFRIO). His interests lie mainly in change management, organizational transformation, learning organization and knowledge management. Before joining HEC in 2001, he served as associate holder of the Bombardier Chair on Networked Organizations. In 1999, he received the prestigious Leaders in Management Education Award granted by the National Post/Price Waterhouse Coopers for the quality of his teaching and his impact on the business world. Before joining the ranks of academia, Professor Jacob had an established career as a consultant, which he continues to pursue. 